\title{
The Fundamental Movement Skill of Male Students with Intellectual Disabilities in Korea
}

\author{
Jae Hoon Jeong, PhD \\ Youn Seon Choi, PhD
}

Korea University, South Korea

Soojin Yoo, PhD

The University of Texas - Rio Grande Valley, USA

Bog Ja Jeoung, PhD

Gachon University, Seoul Korea

doi: 10.19044/ejes.v4no1a62ＵRL:http://dx.doi.org/10.19044/ejes.v4no1a62

\begin{abstract}
This study was conducted to examine the Fundamental Movement Skills (FMS) levels of male students with intellectual disabilities between the ages of 10 and 18 years old. A total of 126 students with intellectual disabilities (IQ < 50), who were attending special education schools in South Korea, participated in the study. FMS were assessed using the Test of Gross Motor Development $2^{\text {nd }}$ edition (TGMD-2), which evaluates locomotor skills (running, hopping, leaping, sliding and jumping) and object control skills (overhand throwing, catching, kicking, hitting, striking and dribbling). Data were analyzed using descriptive statistics and ANOVA with 95\% confidence intervals, and the level of significance set at $\mathrm{p}<.05$. The results showed that the older students had significantly better scores on all locomotor and object control skills except kicking. Higher proportions of students demonstrated mastery of performance criteria for the subset of locomotor and object control skills that involved only leg or arm movement, than for the subset that required coordinated body and arm movement.
\end{abstract}

Keywords: Fundamental Movement Skills, Intellectual Disability, TGMD-2, Special Education School.

\section{Introduction}

The reason to assess and measure Fundamental Movement Skills (FMS) is to evaluate the development of gross motor skills, in terms of FMS mastery. Such evaluation provides information about which sports and activities students should practice or avoid, and which specific skills and coordinated movements they need to develop (Oakley and Booth 2004). 
FMS proficiency in childhood has been shown to influence participation in physical activities, heighten physical activity(PA)in childhood has also been associated with positive health outcomes (Ekelund et al 2004; Strong et al. 2005).

FMS association with PA has caused teacher and coach of sports or specialist to actively recommend the inclusion of FMS training in physical activity program plan(Haywood and Gerchell 2005; Bailey 2006). Generally, children have FMS mastery by about age 12, but children with intellectual disabilities might exhibit low levels of FMS. For this reason, they have lower participation in regular sports activities and get less exercise, which can lead to a "negative spiral of engagement" in children with low levels of FMS(Capio and Rotor 2010; Gallahue and Ozmun 2002; Hardy et al. 2010; Williams et al.2008). It is was important for children to participate in physical activity for their enjoyment, wellbeing, physical fitness, health, and social development; children who exercise have a lower likelihood of becoming obese, and a reduced risk of cardiovascular disease(Capio et al. 2014; Piek et al. 2012). The acquisition of FMS is a consecutive process that is influenced by various internal and external factors including biological, psychological, social, motivational, and cognitive factors, and FMS can be acquired through a range of active play experiences and structured programs(Hardy et al. 2010; Oakley et al. 2001; Sun et al 2011.

Children with intellectual disabilities show delayed development compared to children of the same age without disabilities(Staples and Reid 2010). Movement developmental delay in children with intellectual disabilities is associated with poor movement control ability, lack of comprehension, and low concentration(Piek et al. 2012). FMS mastery may be negatively affected by low IQ, low cognitive ability, and low perceptual ability. Delay in movement development may cause children with intellectual disabilities to have fewer opportunities to participate in physical and sports activities, leading to lack of self-confidence and motivation (Westendorp et al. 2011; Vandorpe et al. 2012; Capio and Rotor 20101). Furthermore, isolation from physical activities hinders children's physical, psychological, and social development and can have a negative influence on their sports participation or physical activity in the future(Westendorp et al. 2011; Fisher et al 2005; Frey et al 2006; Ulrich 2000).

The Test of Gross Motor Development $2^{\text {nd }}$ edition (TGMD-2), a common and frequently used method of assessing FMS (Ulrich 2000) has been validated for children aged 3-10 years old. A Korean version of the TGMD-2, created by Park(2008) has been demonstrated to be valid and reliable for elementary school students from the first to the sixth grade. Several studies have evaluated FMS in children from the ages of 3 to 12 years old, and reported that the acquisition of FMS is nearly completed by 
the age of 12(Ulrich 2000; Park, 2008; Bakhtiari et al. 2011; Choi and Roh 2011; Lee et al. 2011). Previous studies have reported that children with intellectual disabilities lag developmentally by $4-5$ years on average(Kang and Kim 2009). However, little research has been conducted on the FMS levels and patterns of children with intellectual disabilities or who are older than 12 years old. Therefore, research is needed to accurately understand the FMS level-s of children with intellectual disabilities, who show low levels of skills in several areas of physical activities and extracurricular activities including locomotor skill and object manipulation. It is necessary to collect preliminary data to develop physical education programs special education schools that will improve the students' FMS. The purpose of this study is to evaluate the FMS levels of male students, with intellectual disabilities who are 10 to 18 years old, attending special education schools.

\section{Methods:}

\section{Participants}

Four special education schools in the Seoul metropolitan area in South Korea participated in the study. Participants were 126 male students with intellectual disabilities between the ages of 10 to 18 . They attended education classes two to three days (1 hour/day) per week. All participants lived in the Seoul metropolitan area, and all of their parents were Korean. We collected basic information on the children such as gender, birth date, physical activity participation, and IQ from a questionnaire we administered to their parents or guardians (Table 1).

Table 1. Demographic Characteristics of the Participants $(\mathrm{N}=126)$

\begin{tabular}{ccllll}
\hline Group & Age & $\mathrm{n}$ & Weight $(\mathrm{kg})$ & Height $(\mathrm{cm})$ & IQ \\
\hline I & 10 & 6 & $30.98 \pm 10.9$ & $135.31 \pm 14.5$ & $39.8 \pm 11.03$ \\
& 11 & 12 & $39.91 \pm 21.6$ & $144.55 \pm 17.7$ & $37.8 \pm 11.9$ \\
& 12 & 11 & $52.95 \pm 19.2$ & $153.6 \pm 11.4$ & $46.2 \pm 11.2$ \\
& Total & 29 & $43.01 \pm 20.2$ & $146.07 \pm 16.0$ & $45.8 \pm 15.2$ \\
\hline II & 13 & 12 & $61.8 \pm 21.9$ & $160.16 \pm 13.0$ & $34.7 \pm 9.1$ \\
& 14 & 16 & $56.73 \pm 15.6$ & $157.1 \pm 7.4$ & $41.9 \pm 11.6$ \\
& 15 & 15 & $59.32 \pm 16.0$ & $165.81 \pm 9.2$ & $37.9 \pm 8.3$ \\
& Total & 43 & $59.02 \pm 17.0$ & $161.37 \pm 10.2$ & $38.46 \pm 10.4$ \\
\hline III & 16 & 12 & $63.92 \pm 15.5$ & $168.13 \pm 7.8$ & $39.6 \pm 12.9$ \\
& 17 & 21 & $60.39 \pm 22.2$ & $163.42 \pm 9.4$ & $32.17 \pm 5.06$ \\
& 18 & 21 & $64.61 \pm 17.2$ & $167.21 \pm 11.1$ & $39.9 \pm 10.6$ \\
& Total & 54 & $62.82 \pm 18.8$ & $165.94 \pm 9.89$ & $37.2 \pm 10.26$ \\
\hline
\end{tabular}

\section{Testing procedure and Instrument}

The TGMD-2 (Test of Gross Motor Development) was used to measure FMS. This instrument was developed by Ulrich(2000) and reconstructed by Park, Choe, and Kim(2009). The TGMD-2 tests locomotor 
and object control skills. The test assigns 30 points to five locomotor movement skills: running (6 points), hopping (6 points), leaping (6 points), sliding (6 points), and jumping (6 points) and 38 points to five object control skills: overhand throwing (5 points), catching (4 points), kicking (4 points), striking (6 points), and dribbling (5 points). The content validity and reliability of this FMS assessment has been previously demonstrated with a high alignment of assessments at 85\% (Park, 2008).

The study participants performed the five locomotor movements and the five object control movements two to three times. They were recorded by a video camera placed 6-7 $\mathrm{m}$ away. Three researchers scored each participant on each TGMD-2 item and average scores were calculated. The statistical analysis was performed with SPSS for Windows version.21 (IBM SPSS Inc., Chicago, IL, USA). Data were analyzed by three separate age groups: 10-12 years old (elementary school), 13-15 years old (middle school), and 16-18 years old (high school). Descriptive statistics, including proportions and means based on the raw scores, were used to describe the participants' skill mastery. Analysis of variance was used to calculate the average values, the standard error, 95\% confidence intervals (CIs), and standard deviation for each item. Linear regression was used as a post-hoc test. Descriptive statistics including proportion and the mean based on the raw score were used to describe the mastery of FMS for separate age groups. Statistical significance was set at $p<0.05$.

\section{Results:}

They have participated in physical education classes 2-3 days (1 hour/day) a week. We analyzed the data based on the age group (10-12 years old: elementary school, 13-15years old: middle school, 16-18years old: high school). Table 2 presents the participants mean scores and standard deviations, and the prevalence (as percentages 95\% CI) of mastery of the 10 skills by age group (10-12 years; $13-15$ years; 16-18years).

Table 2. Fundamental Movement Skills among Students with Intellectual Disabilities

\begin{tabular}{|c|c|c|c|c|}
\hline \multirow{2}{*}{$\begin{array}{l}\text { Fundamental Movement } \\
\text { Skills }\end{array}$} & \multicolumn{3}{|c|}{ Score, Mean \pm SD (95\%CI) } & \multirow[b]{2}{*}{$p$-value } \\
\hline & 10-12aged $(\mathrm{n}=29)$ & 13-15aged $(n=43)$ & 6-18aged $(n=54)$ & \\
\hline Locomotor skills & $6.85 \pm 5.7(3.9-9.7)$ & $10.72 \pm 6.2(8.5-12.9)$ & $13.32 \pm 7.3(11.3-15.3)$ & $.000^{* * * *}$ \\
\hline Running & $2.39 \pm 1.4(1.8-2.9)$ & $2.66 \pm 1.4(2.2-3.0)$ & $3.33 \pm .95(2.9-3.7)$ & $.005^{* *}$ \\
\hline Hopping & $.95 \pm 1.4(.08-1.8)$ & $2.53 \pm 2.1(1.8-3.2)$ & $2.88 \pm 2.3(2.2-3.5)$ & $.001^{* * *}$ \\
\hline Sliding & $1.30 \pm 2.0(.4-2.2)$ & $2.33 \pm 2.2(1.6-3.0)$ & $2.97 \pm 2.2(2.3-3.6)$ & $.006^{* *}$ \\
\hline Jumping & $1.39 \pm 1.2(.73-2.0)$ & $2.23 \pm 1.6(1.7-2.7)$ & $2.4 \pm 1.7(2.0-2.9)$ & $.020^{*}$ \\
\hline Leaping & $.60 \pm 1.5(-.04-1.2)$ & $.48 \pm 1.1(-.01-.98)$ & $1.33 \pm 2.0(.86-1.7)$ & $.043^{*}$ \\
\hline Object control skills & $6.85 \pm 5.05(4.5-9.1)$ & $10.51 \pm 5.3(8.7-12.2)$ & $12.43 \pm 5.1(10.8-14)$ & $.001^{* * * *}$ \\
\hline Striking a stationary ball & $2.42 \pm 1.6(1.7-3.1)$ & $3.01 \pm 1.5(2.4-3.5)$ & $3.52 \pm 1.4(3.0-3.9)$ & $.010^{* *}$ \\
\hline Stationary dribbling & $.72 \pm 1.18(-.11-1.5)$ & $1.73 \pm 1.9(1.1-2.3)$ & $2.19 \pm 2.0(1.6-2.7)$ & $.003^{* *}$ \\
\hline Catching & $1.40 \pm 1.2(.8-2.0)$ & $2.41 \pm 1.4(1.9-2.8)$ & $2.69 \pm 1.3(2.2-3.1)$ & $.001^{* * *}$ \\
\hline Kicking & $1.45 \pm 1.2(.88-2.0)$ & $1.86 \pm 1.2(1.4-2.2)$ & $2.32 \pm 1.3(1.9-2.7)$ & .147 \\
\hline Overhand throwing & $.85 \pm 1.03(.35-1.3)$ & $1.48 \pm 1.2(1.11-1.8)$ & $1.68 \pm 1.04(1.3-2.0)$ & $.009^{* *}$ \\
\hline
\end{tabular}

Significance levels: $p<0.001^{* * *}, p<0.01^{* *}, p<0.05^{*}$ 
The older students' mean FMS scores were significantly higher than those of the younger students for all skills except for kicking. The overall scores for mastery of locomotor skills were $47.57 \%$ for $10-12$ years old, $38.28 \%$ for $13-15$ years old, and $24.46 \%$ for $16-18$ years old. The prevalence of mastery differed across FMS. All age groups had the heist scores for mastery of running (66.6\% for $10-12$ years old, $53.2 \%$ for $13-15$ years old, and $47.8 \%$ for $16-18$ years old), Scores were lower for sliding (59.4\%, $46.6 \%, 26.6 \%$ respectively), hopping (59.4\%, 42.2\%, 15.8\% respectively), jumping (40\%, 37.2\%, 2.3\% respectively), and leaping (22.2\%, 8.0\%, 10.0\% respectively). Overall scores for mastery of object control skill was $51.79 \%$ for $10-12$ years old, $43.79 \%$ for $13-15$ years old, and $28.5 \%$ for $16-18$ years old. Scores for mastery of catching were $67.3 \%, 60.3 \%$, and $35 \%$ respectively; striking $58.7 \%, 50.2 \%$, and $40.3 \%$ respectively; dribbling $54.8 \%, 43.3 \%$, and $18 \%$ respectively; kicking $46.4 \%, 37.2 \%$, and $29 \%$ respectively; throwing $33.6 \%$, $29.6 \%$, and $17 \%$ respectively. These results show that the proportion of students with mastery of object control skills was higher than the proportion of students with mastery of locomotor skills.

Figures 1 and 2 showed that leaping and hopping performance mastery scores were lower than running, jumping, sliding in locomotor skill. There were showed that the most lower score performance is arms swing to forward and backward movement in running criteria, and upper body slant forward movement in leaping, arms swing can make thrust movement in hoping, arms extension forcefully forward and upward reaching full extension and, arms are thrust downward during landing movement in jumping, step sideways with lead foot followed by a slide of the trailing foot to point next to the lead foot in sliding. Also, In Objective control skill, kicking criteria was the most lower score than others criteria. There were showed movements of the most lower score is caught by hands only movement in catching, in throwing was backward and upward of throwing hand, transfers body weight to front foot in striking, bounce level is regularly when control of ball movement in dribbling, an elongated stride or leap immediately prior to ball contact in kicking. Although high performance was shown in locomotor skills, namely jumping and landing movements with two feet together, as well as horizontal movements such as sliding, low performance was shown in movements that require propulsion using arms and feet, as well as movements that require arm and foot coordination. 
Figure 1. Demonstrated mastery of each performance criteria for the locomotor skills

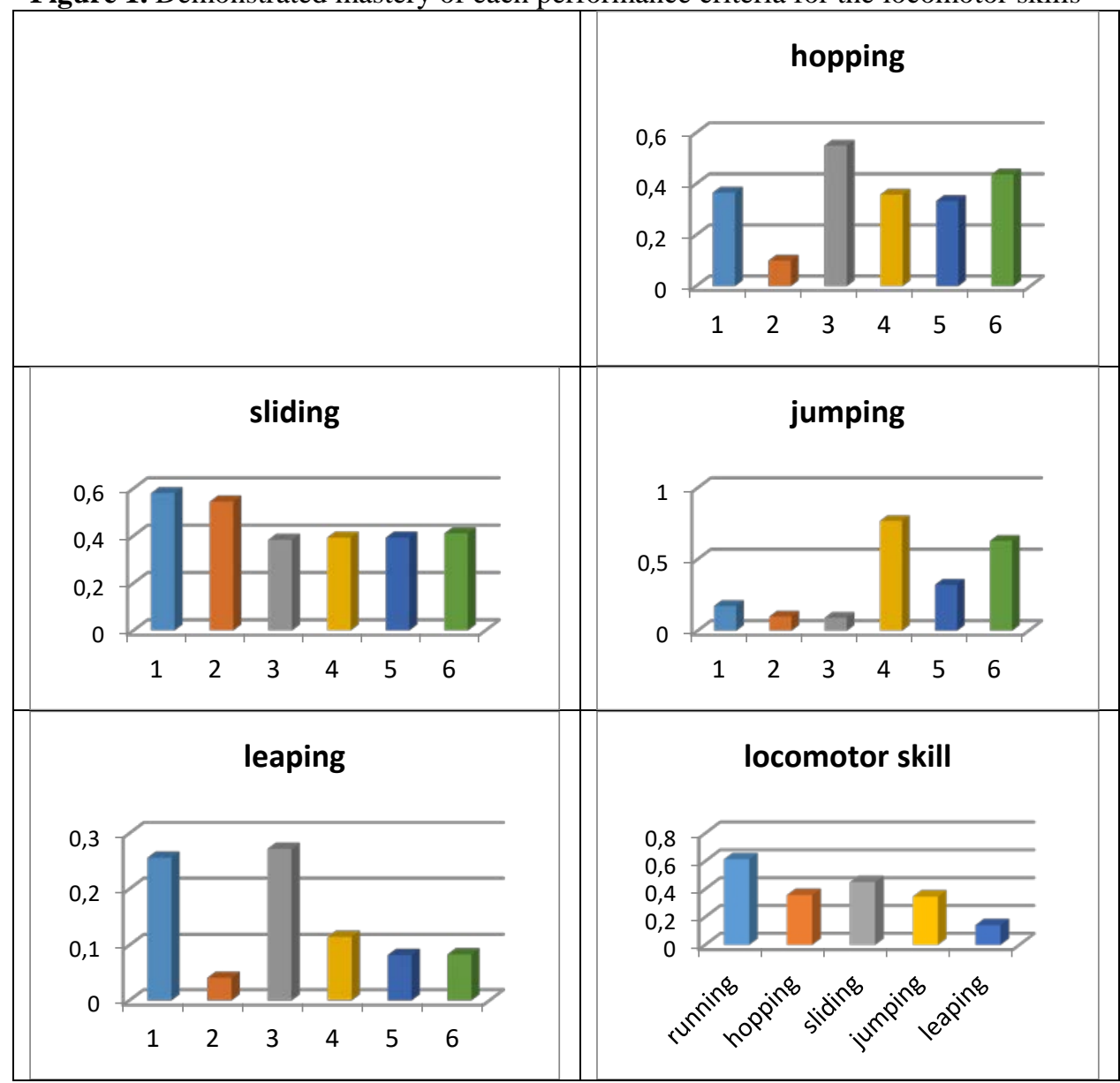




\begin{tabular}{|c|c|}
\hline running & $\begin{array}{l}\text { 1. arms move in opposing direction to legs, elbows bent } \\
\text { 2. arms swing forward and backward } \\
\text { 3. upper body slants forward } \\
\text { 4. narrow foot placement landing on heel or toe } \\
\text { 5. Non-supported leg bent approximately } 90 \text { degree }\end{array}$ \\
\hline hoping & $\begin{array}{l}\text { 1. arms move in opposing direction to leg and elbow } \\
\text { 2. arms swing can make thrust } \\
\text { 3. upper body slant forward } \\
\text { 4. non-support leg swings rhythmically forward and backward } \\
\text { 5. arms flexed and swing forward to produce force } \\
\text { 6. take off \& lands } 3 \text { consecutive times on preferred. }\end{array}$ \\
\hline jumping & $\begin{array}{l}\text { 1. preparatory movement includes arms back swing } \\
\text { 2. arms extension forcefully forward and upward reaching full extension } \\
\text { 3. arms are thrust downward during landing } \\
\text { 4. take off both feet simultaneously } \\
\text { 5. forcefully forward and knee movement bent more than 90degree } \\
\text { 6. land on both feet simultaneously }\end{array}$ \\
\hline leaping & $\begin{array}{l}\text { 1. arm move in opposing to leg } \\
\text { 2. upper body slant forward } \\
\text { 3. a period where both feet are off the ground longer than running } \\
\text { 4. forward reach with the arm opposite the lead foot } \\
\text { 5. maintains a rhythmic pattern for four consecutive leaping }\end{array}$ \\
\hline sliding & $\begin{array}{l}\text { 1. arms bent and lifted above more than waist } \\
\text { 2. body turned sideways to shoulders are aligned with the line on the floor } \\
\text { 3. a step sideways with lead foot followed by a slide of the trailing foot to point next to the lead } \\
\text { foot } \\
\text { 4. showed fly phase } \\
\text { 5. a minimum of four continuous step-slide cycles }\end{array}$ \\
\hline
\end{tabular}


Figure 2. Demonstrated mastery of each performance criteria for the objective control skills

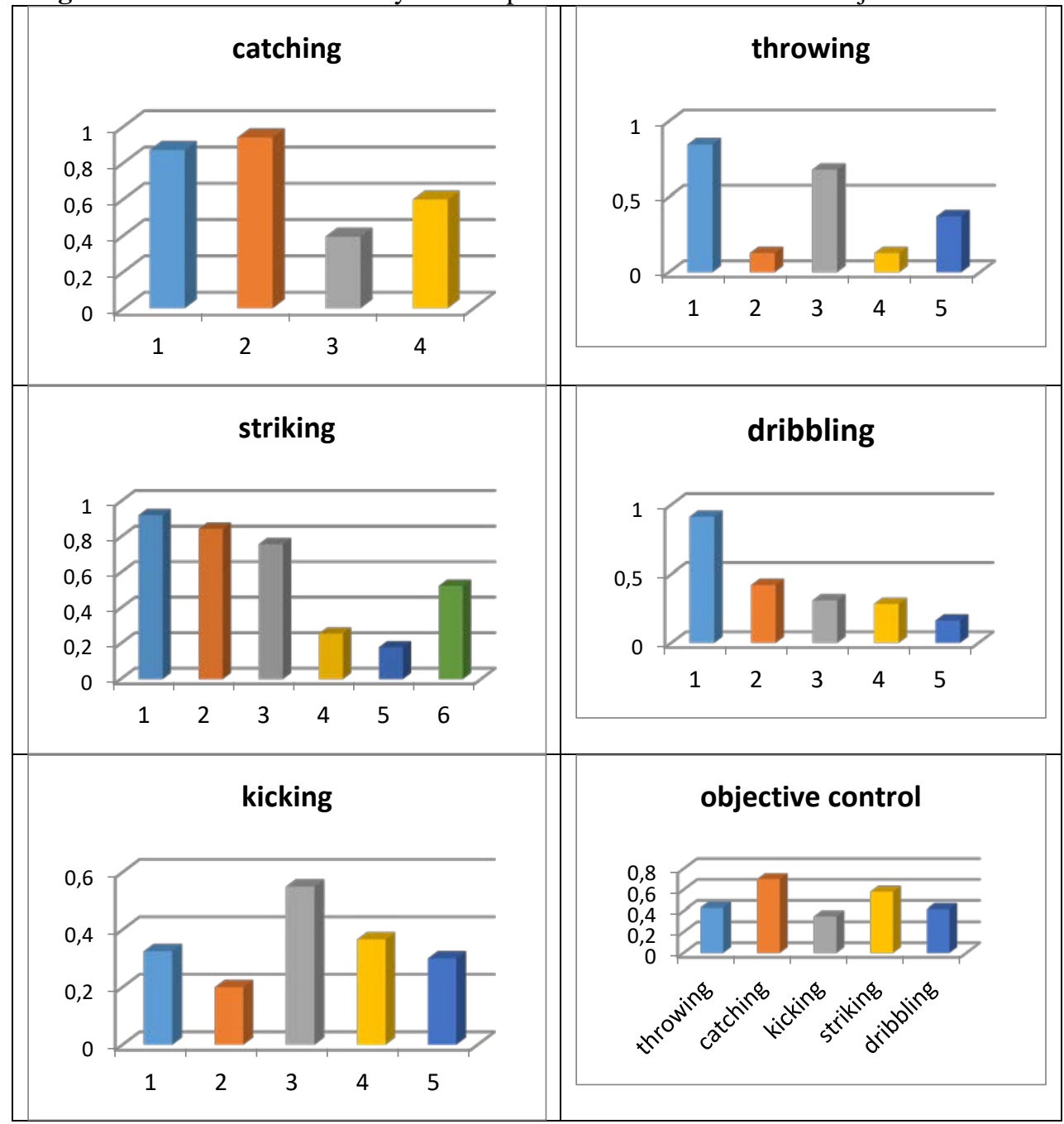




\begin{tabular}{|c|l|}
\hline dribbling & $\begin{array}{l}\text { 1. contact ball with one hand at about belt level } \\
\text { 2. knee bent when dribbing } \\
\text { 3. ball contacts surface in front or to the outside of foot on the preferred side } \\
\text { 4. maintains control of ball for five consecutive bounces } \\
\text { 5. bounce level is regularly when control of ball }\end{array}$ \\
\hline striking & $\begin{array}{l}\text { 1. dominant hand grips bat above non-dominant hand } \\
\text { 2. non-preferred side of body faces the imaginary tosser with feet parallel } \\
\text { 3. bat swing showed diagonal (above- dawn-horizontal) } \\
\text { 4. hip and shoulder rotation during swing } \\
\text { 5. transfers body weight to front foot } \\
\text { 6. bat contacts ball }\end{array}$ \\
\hline catching & $\begin{array}{l}\text { 1. preparation phase where hands are in front of the body and elbows are flexed } \\
\text { 2. arms extend while reaching for the ball as it arrives } \\
\text { 3. ball is caught by hands only } \\
\text { 4. can catch well }\end{array}$ \\
\hline kicking \\
$\begin{array}{l}\text { 1. rapid continuous approach to the ball } \\
\text { 2. an elongated stride or leap immediately prior to ball contact } \\
\text { 3. non-kicking foot placed even with or slightly in back of the ball } \\
\text { 4. kick ball with in step of preferred foot(shoelaces) or toe } \\
\text { 5. hip and kicking foot rotation }\end{array}$ \\
\hline throwing \\
$\begin{array}{l}\text { 1. windup is initiated with downward movement of hand/arm } \\
\text { 2. backward and upward of throwing hand } \\
\text { 3. rotates hip and shoulder to a point where the nonthrowing side faces the wall } \\
\text { 3. weight is transferred by stepping with the foot opposite the throwing hand } \\
\text { 4. follow- through beyond ball release diagonally across the body toward the } \\
\text { nonpreferred side }\end{array}$ \\
\hline
\end{tabular}

In particular, a lower performance was shown in leaping movements, relative to other movements. Although high performance was shown in object control skills, namely throwing movements with the hands, low performance was shown in movements that use the lower body or require arm and foot coordination. In terms of kicking, low performance was shown in runningstart movement or step movement, but high performance was shown in the simple movement of touching a ball with the toe. In terms of striking, high performance was shown in simple movement of grabbing a bat, but low performance was shown in the coordination of movements that use the arms and waist. 


\section{Discussion}

This study demonstrates that age influences the FMS performance capability of male students with intellectual disabilities (IQ < 50); the older students showed higher mastery of skills involving simple movements that use the arms and legs, compared to movements that require coordination of the arms, legs, and torso. In other words, they showed lower levels of the locomotor skills, of hopping and leaping, compared to running, jumping, and sliding. Moreover, in terms of the object control skills, they showed the highest level of mastery for striking movements but lower mastery of movements that require coordination of the arms, legs, and lower body, such as dribbling and throwing. These results may indicate that as intellectually disabled children pass through puberty and become teenagers through puberty, physical changes in length of arms and legs, body composition, and muscle strength, influence their FMS.

Furthermore, the results may indicate that FMS is positively influenced by performing repeated exercises through continuous participation in physical education or physical activities beginning in the lower grades as by the higher grade students better FMS performance, compared to the lower grade students. Many previous studies have reported that FMS are related to cognitive ability and physical activities(Westendorp 2011; Kim and Lee 2013; Bastik et al. 2011).

The results of this study, in which only students with IQ's of 50 were analyzed, show that FMS scores increases with age despite intellectual disabilities, and this pattern positively correlates to physical growth and development, as well as to repeated participation in physical activities. Repeated participation in physical activities is thought to be a particularly important factor in the development and acquisition of FMS in students with intellectual disabilities. In this study, the level of FMS acquisition in elementary students with intellectual disabilities (10-12 years old) was quite low, with scores of $24.46 \%$ for locomotor and $28.5 \%$ for object control skills; middle-school students (13-15 years old) showed $41.03 \%$ mastery of object control skills, and high-school students showed $49.68 \%$ mastery of object control skills. These levels are all below the levels of normal preschool students. The FMS movement acquisition level of middle-school students with intellectual disabilities who have an IQ below 50 is comparable to the $42 \%$ mastery of 4-year-old normal preschool students reported by Hardly et al (2010). Even after entering middle or high school, students with intellectual disabilities who have an IQ below 50, have a much lower FMS acquisition level than normal students, and experience difficulties in organized sports activities or physical activity programs. Therefore, the development of exercise programs to improve FMS in students with 
intellectual disabilities who have an IQ below 50, is necessary. This study's results suggest that in developing an exercise program 0that takes into account the developmental delay of movements in students with intellectual disabilities, the addition of movement exercises that require the coordination of many body parts, as well as exercises that promote chest and limb movements must be considered.

\section{Conclusion}

This study demonstrated that while students with intellectual disabilities who have an IQ below 50 displays lower FMS performance levels relative to normal students, their FMS improves with age. Therefore, when planning a physical activity program for students with intellectual disabilities and low FMS, it is necessary to include active and repetitive exercises, to improve their skill performance capability. Such exercise programs should start from the lower grades, because continued participation in such activities over time is thought to further improve FMS performance capability with age. In addition, it is important to note that lower performance capability was observed in complex movements requiring coordination of the arms, legs and torso, compared to simple movements using only arms or legs. Therefore, in considering education to improve the fundamental movement performance capability of students with intellectual disabilities, the addition of complex performance movements and exercises that require the coordination of multiple body parts should be considered. Appropriate exercise programs may help improve the levels of FMS necessary in the daily lives of students with intellectual disabilities, in addition to the contributing to the maintenance of their health, and quality of life.

There were several limitations in this study. First, the study relied solely on IQ to distinguish the degree of intellectual disability of the participants, but did not consider the psychosocial factors, or the interest levels of the participants in certain exercises. The study's IQ range of 30 to 50 limited the diversity of degree of intellectual disability of the participants. Despite these limitations, the study's design had several. First, the study used as a measuring device a version of the TGMD-2 that had been restructured to evaluate nationally representative data. In addition, this study was the first with a large-scale participation of Korean students with intellectual disabilities. Another advantage of this study may be that the measurements included detailed items for evaluating the FMS performance capability of students with intellectual disabilities. Additional studies that consider other factors that may influence the FMS of students with intellectual disabilities are necessary to more accurately understand their FMS development. 


\section{References:}

Bailey, R. (2006). Physical education and sport in schools: a review of benefits and outcomes. Journal of School Health, 76, 397-401.

Bakhtiari, S., Shafinia, P., Ziaee, V. (2011). Effects of selected exercises on elementary school third grade girl students' motor development. Asian Journal of Sports Medicine, 2 (1), 51-56.

Bastik, C., Kalkavan, A., Yamaner, F., Sahin, S., \& Gullu, A. (2011). Investigation of basic motor skills according to TGMD-2 test on male athletes of 10 ages group who participated to competitions in individual, team and racket sports branches. Procedia - Social and Behavioral Sciences, 28, 421-425.

Capio, C. M., Sit, C. H., Eguia, F. K., Abernethy, B., \& Masters, R. S (2014). Fundamental movement skills training to promote physical activity in children with and without disabilities. Journal of sport health science, 1 , 1-9.

Capio, C. M., Rotor, E. R. (2010). Fundamental Movement Skills among Filipino Children with Down syndrome. Journal of Exercise Science \& Fitness,8 (1), 17-24.

Choi, B. K., Roh, H. K. (2011). The relationships among the cognitive ability and adaptive behavior development on the gross motor proficiency and gross motor development in children with intellectual disabilities. Korean Journal of Adapted Physical Activity \& Exercise, 19, (1), 15-28.

Ekelund, U., Yngve, A., Berge, S., Westerterp, K., Sjöström, M. (2004). Body movement and physical activity energy expenditure in children and adolescent: how to adjust for differences in body. The American Journal of Clinical Nutrition, 851-6.

Fisher, A., Reilly, J., Kelly, L. A., Montgomery, C., Williamson, A., Paton, J. Y., \& Grant, S. (2005) Fundamental movement skills and habitual physical activity in young children. Medicine and Science in Sports and Exercise, 37 (4), 684-688.

Frey, G. C., Chow, B. (2006). Relationship between BMI, physical fitness, and motor skills in youth with mild intellectual disabilities. International Journal of Obesity, 30 (5), 861-867.

Gallahue, D. L., Ozmun, J. C. (2002). Understanding motor development: infants, children, adolescents, adults (5th ed.). Dubuque, Iowa: McGrawHill.

Hardy, L., King, L., Farrell, L., Macniven, R., \& Howlett, S. (2010). Fundamental movement skills among Australian preschool children. Journal of Science and Medicine in Sport, 13 (5), 503-508.

Haywood, K., Gerchell, N. (2005). Life span motor development. Human Kinetics, Champaign, IL. 
Kang, Y., Kim, Y. (2009). The relationship among fundamental motor sill, cognitive development and adaptive behavior in children with Down syndrome. Journal of Physical Education, 48 (3), 517-528.

Kim, C. I., Lee, K. Y. (2013). The relationship or developmental trend between locomotion skill and physical fitness in early childhood: Based on 2, 3, 4, 5 years old. Korean Journal of Physical Education,52 (2), 613-625.

Lee, Y. C., Choi, M. R., Jeoung, B. J. (2011). The effects of exercise program on objective control skill of elementary school students with intellectual disability. Journal of Korean Physical Education Association for Girl and Women, 25 (2), 81-89.

Oakley, A. D., Booth, M. L. (2004). Mastery of fundamental movement skills among children in New South Wales: prevalence and sociodemographic distribution. Journal of Science and Medicine in Sport, 7 (3), 358-372.

Oakley, A. D., Booth, M. L., Patterson, J. W. (2001). Relationship of physical activity to fundamental movement skills among adolescents. Medicine and Science in Sports and Exercise, 33 (11), 1899-1904.

Park, S. H. (2008). Development of the fundamental movement rating system for school-aged children in Korea: Validity and reliability on objectcontrol skill test items. Korean Journal of Sport Psychology, 19 (4), 187199.

Park, S. H., Choe, C. N., Kim, M. Y. (2009). Development of the fundamental movement rating system for Korea children: Establishing evaluation standards and computer-based software program. Korean Journal of Sport Science, 20 (3), 594-611.

Piek, J., Hands, B., Licari, M. (2012). Assessment of motor function in the preschool period. Neuropsychology Review, 22, 402-413.

Staples, K. L, Reid, G. (2010) Fundamental movement skills and autism spectrum disorder. Journal of Autism developmental disorder, 40, 209-217. Strong, W. B., Malina, R. M., Blimkie, C. J, Daniels, S. R., Dishman, R. K., Gutin, B., Hergenroeder, A. C., Must, A., Nixon, P. A., Pivarnik, J. M., Rowland, T., Trost, S., Trudeau, F. (2005). Evidence based physical activity for school-age youth. The Journal of Pediatrics, 146, 732-737.

Sun, S. H., Sun, H. L., Zhu, Y. C, Huang, L. C., \& Hsieh, Y. L. (2011). Concurrent validity of Preschooler Gross Motor Quality Scale with Test of Gross Motor Development-2. Research Developmental Disabilities, 32 (3), 1163-1168.

Ulrich, D. A. (2000). Test of gross motor development (2nd ed.). Austin, Tex: PRO-ED.

Vandorpe, B., Vandendriessche, J., Vaeyens, R., Pion, J., Matthys, S., Lefevre, J., Lenoir, M. (2012). Relationship between sports participation and 
the level of motor coordination in childhood: a longitudinal approach. Journal of Science Medicine in Sport, 15 (3), 220-225.

Williams, H. G., Pfeiffer, K. A., O'Neill, J. R., Dowda, M., McIver, K. L., Brown, W. H., \& Pate, R. R.(2008). Motor skill performance and physical activity in preschool children. Obesity (Silver Spring), 166 (6), 1421-1426. Westendorp, M., Houwen, S., Hartman, E., \& Visscher, C. (2011) Are gross motor skills and sports participation related in children with intellectual disabilities? Research Developmental Disabilities, 32 (3), 1147-1153.

Yang, J., Porretta, L. (1999). Sport/Leisure skill learning by adolescents with mild mental retardation; A four-step strategy. Adapted Physic Activity Quarterly, 16 (3), 300-315. 